\title{
Buddhism on the brain
}

\section{Many religious leaders find themselves at odds with science, but the head of Tibetan Buddhism is a notable exception. Jonathan Knight meets a neurologist whose audience with the Dalai Lama helped to explain why.}

$\mathrm{O}$ ne of the first things people discover when they meet His Holiness the Dalai Lama is that the head of Tibetan Buddhism likes a good laugh. "He jokes all the time," says Fred Gage, a neuroscientist at the Salk Institute for Biological Studies in La Jolla, California, who met the spiritual leader for the first time in October. "He has a great sense of humour."

This is probably a good thing. The occasion for this meeting - a research conference held at the Dalai Lama's headquarters in Dharamsala, India - included a presentation of evidence that people in good spirits are better able to control their blood sugar levels. Other talks suggested that meditation can transform emotions and that daily experiences can alter the expression of genes. Gage presented his research into how the brain can remake itself throughout life.

It was the 12th time since 1987 that the Dalai Lama has convened leading psychologists and neurobiologists to hear the latest scientific thinking in fields related to the human mind. These meetings are organized by the Mind \& Life Institute in Louisville, Colorado, which was established in the 1980s to promote communication between science and Buddhism. But much of the credit for this open communication goes to the Dalai Lama himself.

\section{Spiritual links}

In accordance with Tibetan tradition, the current Dalai Lama, Tenzin Gyatso, was recognized as the 14th reincarnation of the Bodhisattva of Compassion in 1937, when he was only two years old. Gyatso has long had an interest in science. When he accepted the Nobel Peace Prize in 1989, he commented: "Both science and the teachings of the Buddha tell us of the fundamental unity of all things." He once said that if he had not been a monk, he would have been an engineer.

Enthusiasm for science seems to extend beyond the spiritual leader. Tibetans, surprisingly enough, were the most strongly represented ethnic group working on the Human Genome Project: although they account for only $0.1 \%$ of the world's population, Tibetans made up about $10 \%$ of the project's workforce (see Nature 425, 335; 2003).

For many Buddhist monks, this interest in science is focused on an intense curiosity about the workings of the brain. Monks typi-

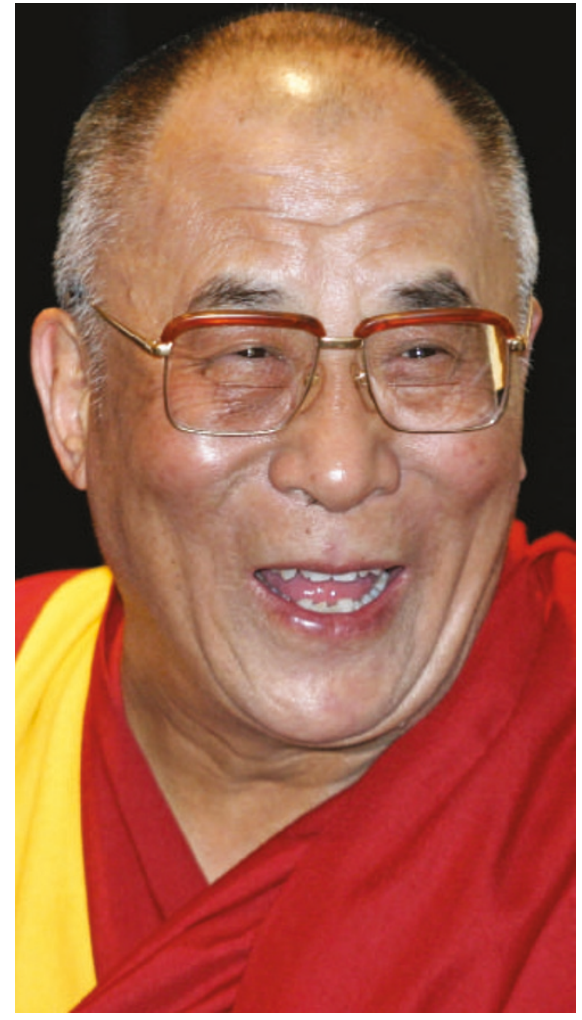

Science with a smile: the Dalai Lama has a deep personal interest in research developments.

cally spend hours in meditation each day, a practice they say enhances their powers of concentration. Highly trained monks report being able to focus on a single object for hours without distraction and to recall complex scenes in exquisite detail. A question that deeply interests the Dalai Lama, and indeed some neuroscientists, is whether these phenomena have a biological basis.

Gage studies the ability of the mammalian brain to change and adapt in adulthood. Before the late 1990s, it was thought that adult brains were more-or-less complete. Learning involved the development of new connections - but no new neurons were born, and when these cells died they were gone forever. Now it turns out that new neurons do grow and our brains are much more flexible than was once believed. As a key component of Buddhist belief is that meditation literally transforms the mind, Buddhists are keenly interested in scientific advances that could help explain this observation.

Gage's talk on 18 October in Dharamsala - seat of the Tibetan government-in-exile since 1960 - kicked off a five-day private conference on 'neuroplasticity'. Gage gave a general primer on the complexity of the nervous system, and then launched into a two-hour presentation of his research targeted at a lay audience. Next to him, the Dalai Lama listened intently, making occasional use of two interpreters to translate into Tibetan things he didn't immediately grasp in English. Also in the audience were the six other presenters and a handful of Buddhist monks.

\section{Lessons learned}

Although the group did not come to any Earth-shattering conclusions about cognition, they did reach a higher understanding of each other, which was the main point of the exercise. For the monks, the sessions may help them deal with modern questions not addressed in traditional Buddhist teachings, such as the issue of the morality of stem-cell research (see page 666). Scientists in turn have plenty to learn from the monks - after centuries of inner contemplation, Buddhists claim to know a thing or two about how the mind behaves.

Richard Davidson, a psychologist at the University of Wisconsin, Madison, and the coordinator of the Dharamsala conference, has learned from the monks through study. He found that certain neural processes in the brain are more coordinated in people with extensive training in meditation, an observation that may be linked to the heightened awareness reported by meditating monks (A. Lutz et al. Proc. Natl Acad. Sci. USA 101, 16369-16373;2004).

Gage says that what particularly impressed him was the Dalai Lama's empirical approach. "At one point I asked: 'What if neuroscience comes up with information that directly contradicts Buddhist philosophy?', says Gage. "The answer was: 'Then we would have to change the philosophy to match the science."'

So far that hasn't been necessary. And if the reported benefits of laughter are correct, there is no need for the Dalai Lama to rein in his sense of humour either. During a discussion of how our childhoods shape who we are, he observed that he liked to play with toy guns as a child and even picked on his brother. "I was the mean one," he said, thereby stabilizing blood sugar levels throughout the room.

Jonathan Knight writes for Nature from San Francisco. 